\title{
Hooks retained detachable Cheek plumper to enhance aesthetics in a completely edentulous patient- A case report
}

\author{
Deepti Kumar ${ }^{*}$, Rajeswari C.L ${ }^{2}$, Srivatsa $\mathbf{G}^{3}$, Rohit Mohan Shetty ${ }^{4}$ \\ ${ }^{1}$ Post Graduate, ${ }^{2}$ Professor, ${ }^{3}$ Principal and Professor, ${ }^{4}$ Professor and HOD, Dept. of Prosthodontics, KLE Societys Institute of Dental \\ Sciences, Bangalore, Karnataka, India
}

*Corresponding Author: Deepti Kumar

Email: deepti4893@gmail.com

\begin{abstract}
Aesthetic reconstruction of original contours is one of the important goals of prosthodontic treatment. Restoration of missing teeth, masticatory function, speech and providing support to the lips and cheeks is prime goal of removable prosthetics. The cheeks lose their support in aged and edentulous individuals. Cheek lifting appliance or cheek plumper is a prosthesis that support and lift the cheeks for aesthetics. This article describes a clinical case where a cheek plumper is being innovatively made detachable by the use of hooks made from orthodontic wire attached to complete denture prosthesis.
\end{abstract}

Keywords: Cheek plumper, Orthodontic wire, Detachable, Hooks.

\section{Introduction}

Aesthetic reconstruction of original contours is one of the important goals of any prosthodontic treatment. Along with the replacements of missing teeth, come the challenges of restoration of masticatory function, speech and providing support to the lips and cheeks as well. ${ }^{1}$

A complete knowledge of the contours to obtain aesthetics is complex yet essential for treatment planning and execution of the treatment demands of patients. The volume of buccal fat may change physiologically or pathologically throughout a person's life. The cheeks lose their support leading further to aged appearance of edentulous patients. It is necessary that in these patients, additional support is provided to the cheeks to maintain their tonicity. This can be done with the help of a device called 'cheek plumper' attached to complete dentures.

Cheek plumper or cheek lifting appliance is essentially a prosthesis that support and lift the cheek to provide necessary support and aesthetics. ${ }^{1}$ Cheek plumper can be of conventional or detachable type. ${ }^{2}$

Conventional cheek plumper is a single-unit prosthesis with an extension near the premolar and molar region that supports the cheeks. Such devices are an integral part of the contour of maxillary denture flanges designed by over contouring denture flanges in the mediolateral and anteroposterior directions within physiologic limits. However, the increased weight and bulk of conventional cheek plumpers could hamper retention of the maxillary complete denture. Conventional cheek plumper can cause muscle fatigue over prolonged use. ${ }^{2}$ Moreover, they cannot be used in patients with limited mouth opening because the additional thickness might hinder the insertion and/or removal of the dentures, whereas detachable cheek plumpers are easy to insert, remove and clean. ${ }^{2}$

Cheek plumpers which are detachable have the advantage of being removable by the patient whenever not required. Patients can only use them when additional aesthetic contours of the cheeks are desirable.
Various modes of attachment for the detachable type of cheek plumpers are available in the literature as advocated and used by various authors. This article describes a clinical case where a cheek plumper is being innovatively made detachable by the use of hooks attached to complete denture.

\section{Case Report}

A female patient 45 years of age presented to the department of Prosthodontics, KLE Institute of Dental Sciences, Bangalore with a complaint of all missing teeth and desired replacement with conventional complete dentures. She also complained that her cheeks being collapsed inwards. [Fig. 1]

On intraoral examination, she presented with a Ushaped maxillary and a $\mathrm{V}$-shaped mandibular arches with moderate edentulous foundations, class I ridge relation and 46-millimetre inter-arch space. Hard and soft palates were normal with House classification of Class I. The tongue position was Wright Class II and the size (House class II) was normal. The Lateral throat form was moderate with class II (Neil's classification) and the mucosa was normal (House Class I) with mixed saliva.

After explaining the different prosthodontic treatment protocols to the patient, she agreed for a removable complete denture along with cheek plumper attachment with respect to maxillary arch.

Maxillary and mandibular primary impressions were made with irreversible hydrocolloid. Full spacer wax was adapted, and custom tray was fabricated using self-cure acrylic resin. Sectional border moulding with low fusing impression compound was performed for both maxillary and mandibular arches followed by final impressions recorded with zinc oxide eugenol impression paste.

Vertical Jaw relation was recorded using combination of techniques i.e phonetics, Niswonger's and swallowing technique. This was followed by chin point manipulation for guiding the mandible to the centric relation and nick and notch method was used to record the same. In this 
stage, modelling wax was adapted onto the maxillary occlusal rim extending distal to buccal frenum to the lateral surface of hamular notch. The occlusal rim served for determining the height for addition of modelling wax laterally. Maxillary tuberosity was a guide for achieving the desired fullness of the cheeks for final prosthesis. The obtained jaw relation was then mounted onto a mean value articulator.

A putty index of the entire maxillary occlusal rim was made from the labial aspect. The index served as a guide for the contours of cheek plumper after trial stage.

Modelling wax depicting the contours of the cheek plumper was then removed and teeth arrangement was done. 2 loops of tentative $0.5 \mathrm{~mm}$ gap were made on the right and left side with $0.9 \mathrm{~mm}$ orthodontic wire and adapted into the wax to serve as an attachment for the cheek plumper. [Fig. 2]

Cheek plumpers were made with wax with the help of putty index. Two hooks were incorporated to the wax cheek plumper such that they hooked onto the loops which were attached on the maxillary denture base. [Fig. 3 and 4]

The waxed-up trial of the maxillary and mandibular denture was confirmed on the patient, the contours were again adjusted according to patient's desire and consent from the patient regarding cheek fullness was done. [Fig 5]

The waxed cheek plumper and the maxillary and mandibular dentures were then processed in the lab by compression moulding technique. They were retrieved, finished and polished. [Fig. 6]

The dentures were tried in the patient's mouth along with the cheek plumper on the day of placement. [Fig. 7]

The maxillary and mandibular dentures were checked for retention, stability and support. Occlusion was verified and selective grinding was performed. The pressure points was addressed, patient was educated to use the dentures and cheek plumper and instructions was given.

The patient was recalled after 24 hours, 3 days and 7 days and the post insertion complaints were addressed.

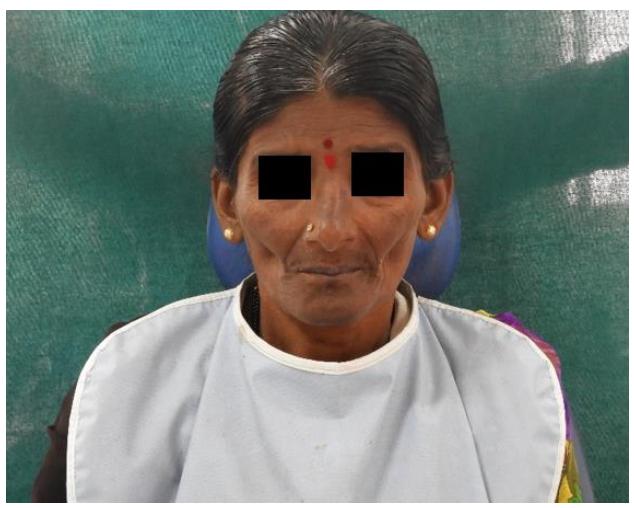

Fig. 1: Preopertative frontal view

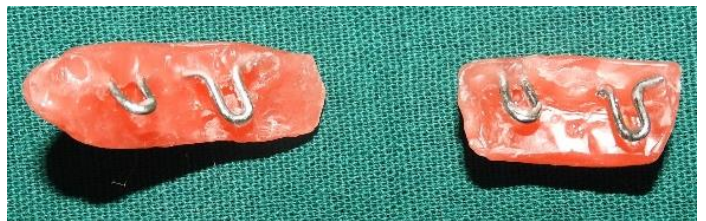

Fig. 2: Waxed up cheek plumper attachments

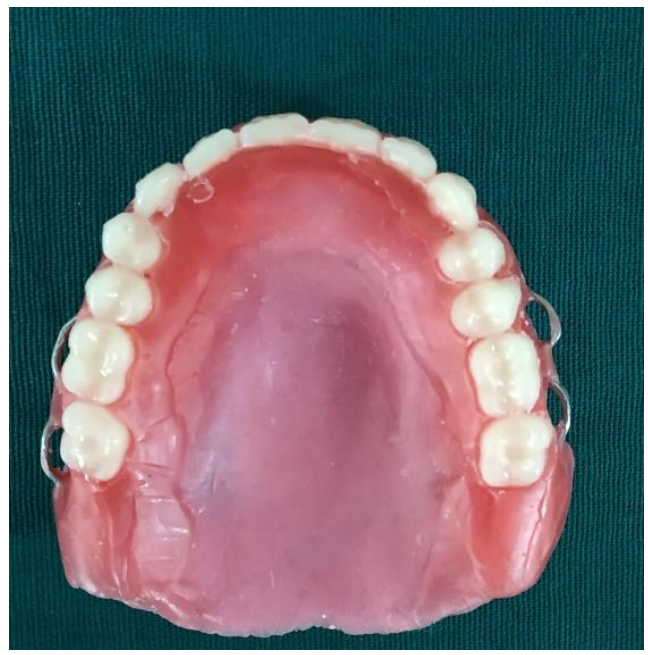

Fig. 3: Embedded orthodontic wire loops on waxed up trial denture

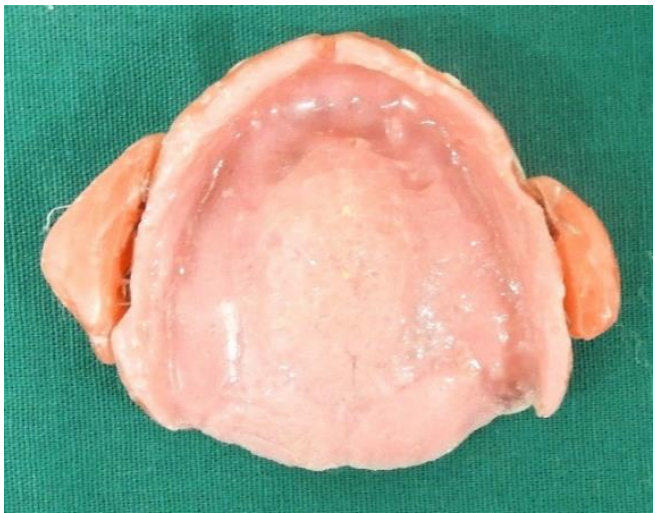

Fig. 4: Tissue Surface of waxed- up denture base with cheek plumper attachments

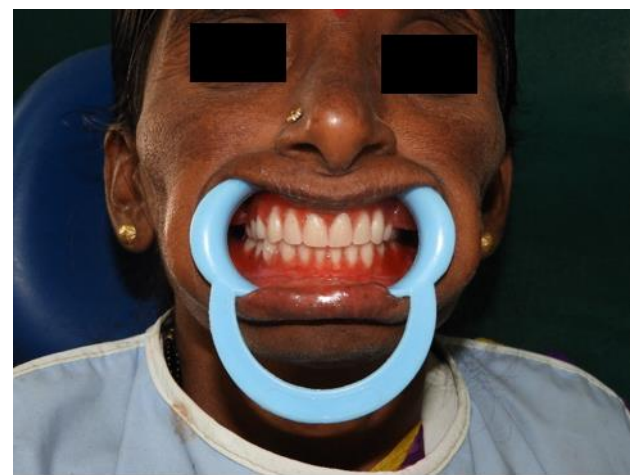

Fig. 5: Try-in of waxed-up trial dentures with cheek plumper attachments

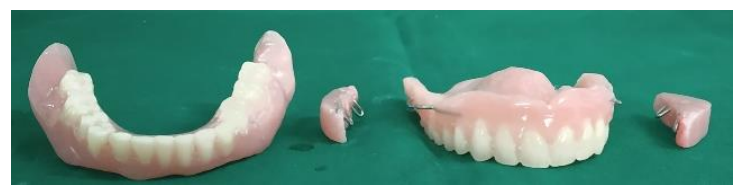

Fig. 6: Heat cured acrylized complete dentures with cheek plumpers 


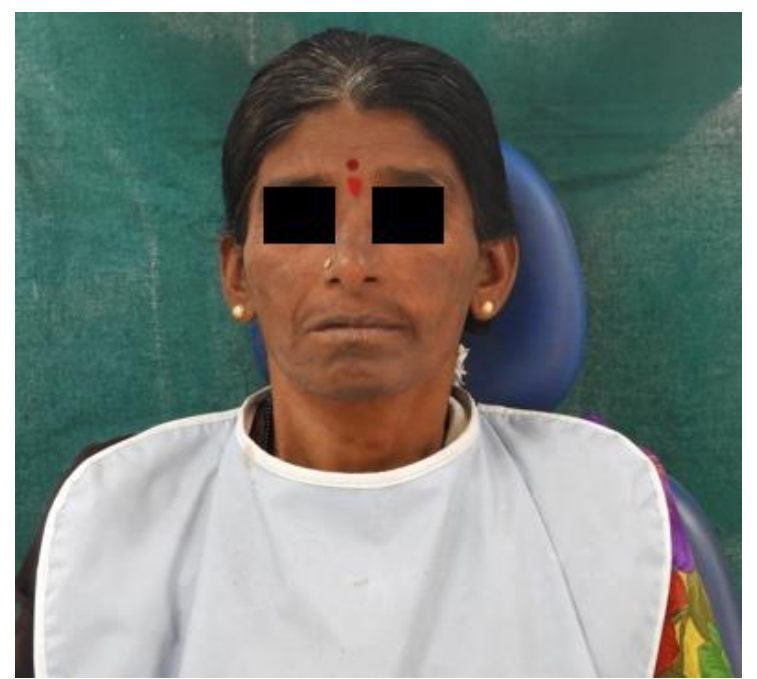

Fig. 7: Post-operative frontal view after denture placement

\section{Discussion}

Tooth loss is an inevitable phenomenon in geriatric age group. Along with loss of the teeth, the oral muscles lose tonicity due to lack of support, as a result leading to sagging cheeks. With increasing age, the patients want normal function as well as aesthetics and hence treatment modalities become more complicated.

Cheek plumpers are non-invasive mode of treatment for supporting and plumping the cheeks to give a more youthful appearance. Detachable cheek plumpers were used to overcome the disadvantages of conventional cheek plumper. The advantages being reduced weight, easy insertion and removal, reduced muscle fatigue and easy to clean. ${ }^{2}$ It also gives an option to the patient to wear the denture without the cheek plumper.

Many case reports have reported placing magnets, ${ }^{3-5}$ die pins, ${ }^{1}$ press fastners, ${ }^{2,6-8}$ brass box ${ }^{9}$ and customized attachment for detachable cheek plumper. ${ }^{10}$ Magnets are advantageous due to small compact size and strong attractive forces, however the magnets used intraorally require replacement due to lack of long-term durability in oral conditions. ${ }^{3}$

Press button retained cheek plumper have poor corrosion resistance, food lodgements and a minimum of 2 buttons for each plumper is preferred for better stability. The press buttons aren't medical grade nor approved for use in the oral cavity. Customized attachment such as brackets, castings and key and keyway are too tedious for fabrication. ${ }^{11}$

Attachments should be cost effective, long lasting and detachable so that the patient can wear at his/her will. It should also resist rotation or movement of plumpers while in function.

Considering all these factors, an innovative method of fabricating detachable cheek plumper was tried with commonly and easily available dental material i.e stainless steel orthodontic wire as it has been used in dentistry for a long time. Stainless steel orthodontic wires have been used in oral environment in dentistry as they are corrosion resistant, cost effective and long lasting.
A $0.9 \mathrm{~mm}$ orthodontic wire was bent with minimal fatigue and customized in such a way that the prosthesis was easily placed and removed by the patient. The loop incorporated in the denture was in alignment within the contours of the denture and self-cleansable. The prosthesis was fabricated so that it could only be removed in one direction.

\section{Conclusion}

In this case, a simple non-invasive treatment protocol to improve aesthetics in a completely edentulous patient was followed. A noble effort was made to improve aesthetics along with function. A complete denture fabricated along with detachable cheek plumpers with $0.9 \mathrm{~mm}$ orthodontic wire as attachment provided a more youthful appearance to the patient with well supported cheeks which aided to boost the self-confidence of the patient and also provided excellent stability during various functions. This innovative method helped to achieve overall well-being of the patient.

\section{Declaration of patient consent}

The authors certify that they have obtained all appropriate patient consent forms. In the form the patient has given her consent for her images and other clinical information to be reported in the journal. The patient understands that her name will not be published and due efforts will be made to conceal her identity, but anonymity cannot be guaranteed.

\section{Financial support and sponsorship}

Nil.

\section{Conflict of interest}

There is no conflict of interest.

\section{References}

1. Raghavendraswamy K.N, Supriya Chauhan, Dhakshani M.R, Anil Kumar Gujjari. Novel die pin Cheek plumper attachmentan innovation to enhance facial aesthetics in completely edentulous patients-case study. Int J Curr Res 2017;9(5):50668-71.

2. Nikita M Virdiya, Jayant N Palaskar, Jyoti Wankhade, Nikhil Joshi. Detachable cheek plumpers with different attachment for improving esthetics in a conventional complete denture: a clinical report. J Prosthetic Dent 2017;117(5):592-6.

3. Rupal J Shah, Pravin Parmar, Arun Soni, Sneha Vyas, Malti Zala, Unconventional complete dentures: Innovative approach in prosthodontics. Int J Healthcare Biomed Res 2014;2(2):12331.

4. Suryakant Chhagan Deogade, Magnet retained cheek plumper in complete denture esthetics: a case report. J Dent 2014;11(1):100-5.

5. Ajit, S Jankar, Madhuri Kamlesh Wadhwani, Suresh Kamble, Vidya Satish Gatkal. Detachable cheek plumper for upliftment of denture esthetics: a case report. Int J Sci Res 2017;6(11):411-2

6. Prachi Aggarwal, Malti Raj Gupta, Salil Pawah, Abhishek Singh. An innovative technique to improve complete denture aesthetics using cheek plumper appliance: case report. Int $J$ Oral Health Med Res 2016;3(2):51-4.

7. Varsharni M Dhakne, Premraj Jadhav, Milind Limaye. Cheek plumper: A unique way to enhance facial aesthetics. Int $J$ Res Rep Dent 2018;1(1):1-4. 
8. Harpreet Singh Saini. Rehabilitating smiles using detachable cheek plumper prosthesis: a case report. Eur J Pharmaceutical Med Res 2017;4(12):457-61.

9. Godwin Da Costa, Meena Aras, Vidya Chitre Praveen Rajagopal, Aradhna Nagarsekar. Cheek plumper with salivary reservoir: An esthetic treatment option for xerostomic patient with sunken cheeks. Dent 2015,5(5):1-3.

10. Nandita N Keni, Meena A Aras, Vidya Chitre. Customised attachments retained cheek plumper prosthesis: a case report. $J$ Indian Prosthodont Soc 2012;12(3):198-200.
11. Prem Bhushan. Customized Cheek Plumper with friction lock attachment for a completely edentulous patient to enhance esthetics: A clinical report. J Prosthodontics 2017;1-5.

How to cite this article: Kumar D, Rajeswari CL, Srivatsa G. Shetty RM. Hooks retained detachable Cheek plumper to enhance aesthetics in a completely edentulous patient- A case report. Int J Oral Health Dent 2019;5(3):136-9. 